\title{
Elaboración de productos de higiene y desinfec- ción en los laboratorios de ciencias de la URACCAN en el contexto COVID-19
}

\section{Preparation of hygiene and disinfection products at URACCAN Science Laboratories in the context of Coronavirus disease (COVID-19)}

\author{
Oswaldo Hernández Rodriguez,1 \\ Elder Alfonso González Brizuela,2 \\ José Milciade Castro Fornos,3 \\ Allan Ray Taylor Torrez,4
}

\section{Resumen}

Dentro del marco de la pandemia originada por el contagio del COVID-19, hasta la fecha no existe un tratamiento específico, ni una vacuna para la prevención, por lo que la mejor manera es evitar exponerse al virus. Es necesario entonces, cumplir con las medidas de desinfección y control que han demostrado minimizar las probabilidades de contagio o infección. En este marco, se desarrolló el presente trabajo experimental, en el Laboratorio de Ciencia de la Universidad de las Regiones Autónomas de la Costa Caribe Nicaragüense (URACCAN), Recinto Nueva Guinea, con el propósito de elaborar insumos de higiene, limpieza y desinfección, obteniéndose como resultados, jabón sólido, hipoclorito de sodio al $4 \%$ y alcohol etílico al $70 \%$. Con base a lo anterior, estos productos son considerados como una alternativa sostenible de lucha frente a la enfermedad, con la perspectiva de disminuir los costos de adquisición y asegurar la disponibilidad de los mismos para la comunidad universitaria.

Palabras clave: COVID-19; Insumos; higiene; desinfección; Laboratorio de Ciencias; URACCAN.

\begin{abstract}
Within the context of the pandemic caused by the spread of COVID-19 where there is no specific treatment, nor a vaccine for prevention, so the best way is to avoid being exposed to the virus. It is then necessary to comply with the disinfection and control measures that have been shown to minimize the chances of contagion or infection. In this process, the present experimental work was developed, in the Science Laboratory of the University of the Autonomous Regions of the Nicaraguan Caribbean Coast (URACCAN), Nueva Guinea Campus, with the purpose of developing hygiene, cleaning and disinfection supplies, obtaining as results, solid soap, $4 \%$ sodium hypochlorite and $70 \%$ ethyl alcohol. Based on the foregoing, these products are considered as a sustainable alternative to fight against the disease, with the perspective of reducing acquisition costs and ensuring their availability for the university community.
\end{abstract}

Keywords: COVID - 19; Supplies; hygiene; disinfection; Science laboratory; URACCAN.

\footnotetext{
1 Doctor en Medicina Veterinaria. Coordinador General de Laboratorios Naturales de la URACCAN, oswaldolabnat@uraccan.edu.ni. https://orcid.org/0000-0002$\underline{9082-7065}$

2 Licenciado en Química. Responsable de Laboratorio de Ciencias, Recinto Nueva Guinea, egonzalezbrizuela@yahoo.es https://orcid.org/0000-0002-2368-9790

3 Licenciado en Biología. Responsable de Laboratorio de Ciencias, Extensión Waslala. castromilciade@yahoo.com; : https://orcid.org/0000-0003-4039-9709

4 Ingeniero Químico. Responsable de Laboratorio de Ciencias, Recinto Bilwi. laboratorioaguaysuelo@uraccan.edu.ni https://orcid.org/0000-0003-0326-9358
} 


\section{Introducción}

A finales de 2019 surgió en Wuhan (China) el SARS-CoV-2, un nuevo coronavirus causante de la COVID-19. Enfermedad infecciosa respiratoria se convirtió en una pandemia que afecta a muchos países del mundo. Según la OMS, la mayoría de las personas (alrededor del 80\%) se recuperan de la enfermedad sin necesidad de tratamiento hospitalario. Alrededor de 1 de cada 5 personas que contraen la COVID19 acaba presentando un cuadro grave y experimenta dificultades para respirar. Las personas mayores y las que padecen afecciones médicas previas como hipertensión arterial, problemas cardiacos, pulmonares, diabetes o cáncer, tienen más probabilidades de presentar cuadros graves. Sin embargo, cualquier persona puede contraer la COVID19 y caer gravemente enferma.

La misma se propaga principalmente a través de las gotitas respiratorias que liberan las personas enfermas al hablar, toser o estornudar. Se cree que el virus podría transmitirse a las manos a través de una superficie contaminada y de allí a la nariz, ojos o la boca, causando una infección. Por consiguiente, las prácticas de prevención personales como lavarse las manos o desinfectarse con alcohol y las prácticas de prevención ambientales como la limpieza y desinfección, son principios importantes que ayudan a reducir el riesgo de exposición al COVID-19 y su propagación.

Por lo que contar con productos de higiene y desinfección es de gran importancia en este nuevo contexto. En este sentido, la Universidad de las Regiones Autónomas de la Costa Caribe Nicaragüense (URACCAN), teniendo Laboratorios de Ciencias, concebidos como: el lugar dotado con los medios necesarios que garantizan la calidad y repetibilidad de resultados de las clases prácticas, experimentos, investigaciones, innovaciones o emprendimientos desarrollados por los estudiantes, docentes e investigadores (URACCAN, 2020), tomó la decisión política de incursionar en la elaboración de jabón, hipoclorito de sodio al $4 \%$ y alcohol al $70 \%$ como proyecto piloto, para contribuir a la satisfacción de la demanda interna y sostenible de productos de higiene, limpieza y desinfección utilizados en la campaña inclusiva y permanente de prevención del COVID-19 de la Universidad.

\section{Revisión de literatura}

Los coronavirus ( $\mathrm{CoV}$ ) según la OPS (2020), son una gran familia de virus que causan enfermedades que van desde el resfriado común hasta enfermedades más graves. Esas infecciones suelen cursar con fiebre y síntomas respiratorios (tos y disnea o dificultad para respirar). En los casos más graves, pueden causar neumonía, síndrome respiratorio agudo severo, insuficiencia renal e incluso, la muerte. La epidemia de COVID-19 fue declarada por la OMS como una pandemia en marzo 2020, por su afectación en muchos países y a un gran número de personas. Las recomendaciones habituales para no propagar la infección incluyen la buena higiene de manos y respiratoria (cubrirse la boca y la nariz al toser y estornudar) y la cocción completa de la carne y los huevos. Asimismo, se debe evitar el contacto estrecho con cualquier persona que presente signos de afección respiratoria, como tos o estornudos.

La mayoría de los virus, incluido el coronavirus, tienen entre 80-120 nm de diámetro, por lo que son realmente nanopartículas y están construidas en tres bloques: el material genético que puede ser ADN o ARN proteínas y lípidos. Se les llama coronavirus por la corona de puntas que se observa alrededor del virus en imágenes de microscopía electrónica. Estas puntas corresponden a las glicoproteínas espiga (S), distribuidas en toda la superficie viral. El ARN es el material genético del coronavirus, en este caso es de cadena sencilla y no segmentada. Las proteínas tienen varias funciones: están involucradas en la ruptura de la célula que van a infectar, ayudan con la replicación del virus y básicamente son un elemento clave en toda la estructura del virus. Los lípidos forman una envoltura alrededor del virus, tanto para proteger como para facilitar la invasión celular y la propagación de las partículas virales. El ARN, las proteínas y los lípidos se autoensamblan para formar el virus. (Oliva, 2020)

Las nanopartículas tienen interacciones complejas con las superficies sobre las que se encuentran; los virus hacen lo mismo. La piel, el acero, la madera, las telas, las pinturas y la porcelana son superficies muy 
diferentes. Se cree que el coronavirus SARSCoV-2 se mantiene activo en superficies afines durante horas, posiblemente un día.

Según Thordarson (2020), el jabón contiene sustancias similares a las grasas conocidas como moléculas anfipáticas, estructuralmente, estas sustancias son muy similares a los lípidos en la membrana del virus. Debido a esta similitud, las moléculas de jabón "compiten" con los lípidos de la membrana del virus. Las moléculas de jabón también compiten con muchos otros enlaces no covalentes que ayudan a las proteínas, el ARN y los lípidos a unirse. El jabón "disuelve" efectivamente el pegamento que mantiene unidos los bloques (su estructura) que componen el virus y más con el agua que le agregas. El jabón también rompe las interacciones entre el virus y la superficie de la piel. Pronto los virus se desprenden y se desintegran debido a la acción combinada del agua y el jabón. La piel es bastante rugosa y arrugada, razón por la cual necesita una buena cantidad de frotamiento y remojo para asegurarse de que el jabón llegue a todos los rincones de su superficie en donde podrían alojarse virus activos.

Los productos a base de alcohol, que incluyen todos los "desinfectantes" y productos "antibacterianos" contienen una solución con alto contenido de alcohol, típicamente 60-80\% de etanol, a veces también con un poco de isopropanol, agua y un poco de jabón. El etanol y otros alcoholes no sólo forman puentes de hidrógeno fácilmente con la envoltura del virus, sino que, como solventes, son más afines a la envoltura de grasa del virus que el agua. Por lo tanto, el alcohol también disuelve la membrana lipídica del virus e interrumpe otras interacciones supramoleculares del virus. Sin embargo, necesitamos una concentración bastante alta (más de 60\%) de alcohol para poder disolver el virus.

La Organización Mundial de la Salud y los Centros de Prevención y Control de Enfermedades de los Estados Unidos de América (EUA) recomiendan a la población en general:

Lavarse las manos frecuentemente, debido a que el jabón desactiva el virus y el agua lo "disuelve" y elimina. Si las manos no estan visiblemente sucias, el método preferido es utilizar un desinfectante a base de alcohol (con una concentración mínima del 7\%) durante 20-30 segundos. Si no se dispone de alcohol ni jabón, se puede usar agua clorada (a una concentración de 0.05\%), pero no es ideal porque el uso frecuente puede provocar dermatitis e irritación de la mucosa respiratoria, lo que podría aumentar el riesgo de infección, asma y otras afecciones (WHO, 2020d; CDC, 2020b)

No está claro cuánto tiempo puede sobrevivir el virus en las superficies, pero la información preliminar sugiere que puede sobrevivir durante mucho tiempo. Por lo tanto, es necesario limpiar todas las superficies y desinfectarlas con frecuencia, especialmente las que han sido tocadas directamente por varias personas. Entre los productos útiles para eliminar el virus están tanto los desinfectantes a base de alcohol, con un porcentaje (etanol/alcohol etílico) al 70\%, como los productos basados en hipoclorito sódico (lejía), capaz de eliminar el virus en la mayoría de las superficies sin causar la irritación del sistema respiratorio.

Tabla 1. Algunas sustancias químicas eficaces y relativamente comunes para inactivar los viriones de SARS-CoV-2 en superficies (EPA, 2020).

\begin{tabular}{|l|l|l|l|}
\hline \multicolumn{1}{|c|}{ Sustancia química } & \multicolumn{1}{c|}{ Concentración mínima de la solución } & $\begin{array}{c}\text { Tiempo mínimo de contacto con las } \\
\text { superficies }\end{array}$ & $\begin{array}{c}\text { Mecanismo de inactivación de los } \\
\text { viriones }\end{array}$ \\
\hline $\begin{array}{l}\mathrm{NaClO} \text { (hipoclorito de sodio) } \\
\text { o Ca (ClO)2 (hipoclorito de } \\
\text { calcio) en solución acuosa, } \\
\text { comúnmente llamado "cloro" }\end{array}$ & $\begin{array}{l}\text { 0.1\% } \\
\text { En la etiqueta de los envases de } \\
\text { desinfectantes con "cloro", el fa- } \\
\text { bricante indica la concentración } \\
\text { a la que se encuentra el "cloro" } \\
\text { en agua. }\end{array}$ & Al menos 10 minutos. & $\begin{array}{l}\text { Estos compuestos oxidan } \\
\text { los enlaces covalentes de las } \\
\text { proteínas de la envoltura y } \\
\text { probablemente de la cápsi- } \\
\text { de del virus. }\end{array}$ \\
\hline
\end{tabular}




\begin{tabular}{|l|l|l|l|}
\hline \multicolumn{1}{|c|}{ Sustancia química } & \multicolumn{1}{|c|}{ Concentración mínima de la solución } & $\begin{array}{c}\text { Tiempo mínimo de contacto con las } \\
\text { superficies }\end{array}$ & $\begin{array}{c}\text { Mecanismo de inactivación de los } \\
\text { viriones }\end{array}$ \\
\hline $\begin{array}{l}\text { Alcohol etílico, conocido sim- } \\
\text { plemente como "alcohol" }\end{array}$ & $\begin{array}{l}\text { 70\% en agua } \\
\text { La mayoría de los envases de } \\
\text { "alcohol" de venta libre en las } \\
\text { farmacias, tienen concentracio- } \\
\text { nes aproximadas a 70\%. La con- } \\
\text { centración se debe consultar en } \\
\text { la etiqueta de cada producto. }\end{array}$ & $\begin{array}{l}\text { Restregar fuerte y dejar } \\
\text { secar. }\end{array}$ & $\begin{array}{l}\text { Emulsifica los lípidos y, por } \\
\text { lo tanto, "desensambla" } \\
\text { la envoltura del virus. Al } \\
\text { desensamblarse, el virus es } \\
\text { inactivado. }\end{array}$ \\
\hline Detergentes & $\begin{array}{l}\text { Consultar instrucciones del } \\
\text { fabricante. }\end{array}$ & $\begin{array}{l}\text { Restregar fuerte durante, al al } \\
\text { menos, 20 segundos. }\end{array}$ & $\begin{array}{l}\text { Los detergentes forman } \\
\text { complejos (micelas) con los } \\
\text { lípidos y las proteínas de la } \\
\text { envoltura del virus. Esto "des- } \\
\text { ensambla" dicha envoltura. } \\
\text { Al desensamblarse, el virus } \\
\text { es inactivado. }\end{array}$ \\
\hline
\end{tabular}

Nota: No se deben mezclar diferentes sustancias, ya que algunas reaccionan químicamente unas con otras y forman vapores tóxicos.

\section{Materiales y métodos}

Este estudio se realizó en el Laboratorio de Ciencias de la Universidad de las Regiones Autónomas de la Costa Caribe Nicaragüense (URACCAN), Recinto Nueva Guinea, con un enfoque experimental en laboratorio por 15 días. Según, Hernández Sampieri (2003), los experimentos de laboratorio se realizan en condiciones controladas en las cuales el efecto de las fuentes de invalidación interna es eliminado, así como el de otras posibles variables independientes que no son manipuladas o no interesan. La muestra seleccionada fue no probabilística experimental, teniendo como variables o elementos, los siguientes: grasa (aceite), bases (sosa), hipoclorito de sodio $(\mathrm{NaClO})$ y grado alcohólico alcanzado.

La práctica experimental de elaboración de jabón, preparación de hipoclorito de sodio al $4 \%$ y la obtención de alcohol pueden ser realizadas de varias maneras. En este caso se utilizaron las siguientes:

Para la fabricación de jabón, se aplicó el método de saponificación de las grasas (Ramos, 2016), consiste en mezclar el aceite vegetal con hidróxido de sodio en un medio líquido, compuesto por agua, transformando la grasa en jabón. El protocolo, que incluye el procedimiento de tratamiento, eliminación y en su caso reciclado de los posibles residuos, se utilizó de forma constante, orientado a mantener el orden en las medidas y aplicación de las diferentes sustancias: agua, aceite, hidróxido de sodio, colorantes y aromatizantes. El proceso de mezcla debe ser suave, continua y en un solo sentido hasta obtener la consistencia ideal para depositar la pasta en los moldes.

La preparación de hipoclorito de sodio al 4\%, se fundamentó en el método de dilución de una sustancia de mayor concentración a otra de menor concentración (Torres, 2016). También cualquier concentración, puede ser utilizada para obtener una solución de hipoclorito diluida utilizando la fórmula siguiente:

El alcohol fue elaborado aplicando el método de la fermentación alcohólica y destilación. Según Herrera et al. (2011), la fermentación alcohólica es un proceso biológico que se obtiene de la mezcla de agua, azúcar y levadura, que se deja en reposo durante 5 días para la obtención del fermento que posteriormente se lleva al destilador para la obtención del alcohol.

Los materiales utilizados para recolectar los datos fueron fichas de artículos científicos y de resumen. Para procesar los datos se usaron tablas descriptivas, figuras, diagramas y procesos. 
Tabla 2. Equipos utilizados para los experimentos

\begin{tabular}{|c|l|}
\hline Cantidad & \multicolumn{1}{|c|}{ Nombre del equipo } \\
\hline 1 & Balanza electrónica \\
\hline 1 & Calculadora \\
\hline 1 & Agitador magnético \\
\hline 1 & Peachimetro \\
\hline 1 & Destilador de alcohol \\
\hline 1 & Estufa de gas con dos quemadores \\
\hline 1 & Bomba de vacío \\
\hline 1 & Fermentador de sustancias \\
\hline
\end{tabular}

Tabla 3. Reactivos utilizados para los experimentos

\begin{tabular}{|l|l|l|}
\hline \multicolumn{1}{|c|}{ Reactivo } & \multicolumn{1}{|c|}{ Fórmula de la sustancia } & \multicolumn{1}{c|}{ Estado de la sustancia } \\
\hline Aceite vegetal & $\mathrm{C}_{18 \mathrm{H}_{34} \mathrm{O}_{2}}$ & Oleoso \\
\hline Hidróxido de sodio & $\mathrm{NaOH}$ & Líquido \\
\hline Hipoclorito de sodio 12\% & $\mathrm{NaClO}$ & Líquido \\
\hline Agua destilada & $\mathrm{H}_{2} \mathrm{O}$ & Líquido \\
\hline Agua pura & $\mathrm{H}_{2} \mathrm{O}$ & Líquido \\
\hline Aromatizante fresa & $\mathrm{C}_{7} \mathrm{H}_{12} \mathrm{O}_{4}$ & Oleoso \\
\hline Colorante amarillo 2G & Identificador 6359-98-4 & Polvo \\
\hline Levadura & Fermento biológico & Pasta \\
\hline Azúcar moreno & C12 $\mathrm{H}_{22} \mathrm{O}_{11}$ & Granulada \\
\hline
\end{tabular}

Tabla 3. Materiales utilizados para los experimentos

\begin{tabular}{|c|l|l|}
\hline Cantidad & \multicolumn{1}{|c|}{ Nombre de los materiales } & \multicolumn{1}{c|}{ Usos } \\
\hline 3 & Probetas de cristal & Medir las cantidades de sustancias \\
\hline 4 & Pipetas de cristal & Extraer y trasladar sustancias \\
\hline 4 & Beaker & Contener y calentar sustancias \\
\hline 2 & Jarras medidoras & Medir sustancias \\
\hline 2 & Varillas de cristal & Agitar sustancias \\
\hline 6 & Cajas de Petri & Para evaluar sustancias \\
\hline 4 & Vidrios reloj & Para hacer prueba de flama \\
\hline 2 & Palas de madera & Para agitar productos irritantes \\
\hline 2 & Baldes plásticos & Para realizar reacciones químicas \\
\hline 1 & Mortero de porcelana & Maceración de sustancias \\
\hline 64 & Moldes plásticos & Para elaborar jabón \\
\hline 1 & Barril plástico con tapa de rosca & Para fermentar sustancias \\
\hline
\end{tabular}




\section{Resultados y discusión}

\subsection{Fabricación de jabón a partir de hidróxido de sodio}

Para la elaboración del jabón se ensayaron tres fórmulas basadas en la concentración de hidróxido de sodio y agua. Los mejores resultados se obtuvieron con la fórmula 3, la que consistió en utilizar $500 \mathrm{ml}$ de agua destilada, $1 \mathrm{~L}$ de aceite vegetal, $270 \mathrm{ml}$ de hidróxido de sodio, $12 \mathrm{ml}$ de aromatizante y $3 \mathrm{~g}$ de colorante. Las sustancias se mezclaron en la misma secuencia con una homogenización suave, constante y en un mismo sentido, hasta que se produce la pasta lista para ser depositada en los moldes. El proceso continuo, con un período de reposo de 24 horas antes de retirarlos del molde, posteriormente se hace la selección y se estiban en lugar seco y fresco para que maduren durante 25 días, antes de ser usados para el lavado de manos o lavado de ropa.

Lo que coincide con Barbosa (2012), que el proceso consiste fundamentalmente en una reacción química que transforma los ácidos grasos en jabón mediante una solución alcalina. Ramos (2016), lo plantea, como la transformación de las grasas mediante un proceso de hidrólisis alcalina donde interviene el agua, grasas e hidróxido de sodio dando como resultado el jabón.
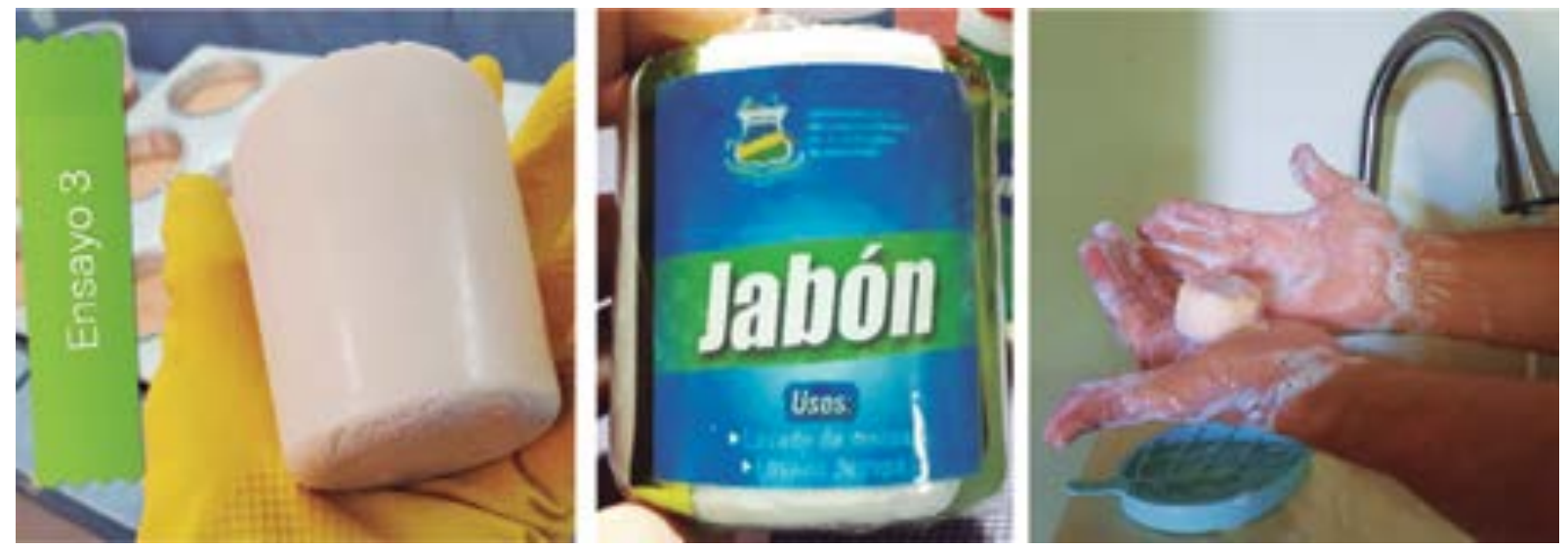

Figura 1. Muestra de jabón elaborado en el Laboratorio de Ciencias de la URACCAN

La valoración de las propiedades físicas después de 10 semanas de elaborado, es un jabón de consistencia dura, compacta y de tacto suave. Además, durante su uso mantiene el color, la fragancia y hace espuma al lavarse las manos. Lo que no concuerda con Barbosa (2012), que la durabilidad del producto será de 3 a 4 semanas, mientras que Ramos (2016), menciona que el jabón deja de ser apto para su uso cuando se produce el enranciamiento, pero no define el tiempo de espera.

En cuanto a las grasas, los aceites vegetales (de girasol y de oliva) dan lugar a jabones muy parecidos. Sin embargo, para futuros experimentos sería importante ensayar con el aceite de coco, que según Kasper (2020), presenta muchas bondades para la producción de jabón, enlistando las económicas y físicas. Entre ellas, mayor consistencia del producto, impresionante poder desengrasante y abundante espuma, incluso en agua salada. Por lo que, se puede retomar como una oportunidad para la reducción de gastos en materia prima, convirtiendo el proceso en más sostenible, tomando en cuenta que el aceite de coco se podría producir en los diferentes Laboratorios Naturales de la URACCAN.

\subsection{Preparación de hipoclorito de sodio al $4 \%$, como agente desinfectante}

El cloro ( $\left.\mathrm{Cl}_{2}\right)$, es uno de los elementos más usados por nuestra sociedad, formando parte de productos en la vida cotidiana, incluso en el agua que bebemos. En muchos casos, es utilizado de manera directa como agente desinfectante que se genera por electrólisis de cloruro sódico junto con la sosa cáustica e 
hidrógeno. $\mathrm{El} \mathrm{Cl}_{2}$ raramente se prepara a escala de laboratorio, ya que son necesarias unas condiciones de almacenamiento determinadas y botellas de presión de distintas capacidades. Sin embargo, se puede obtener el hipoclorito de sodio, que es una solución acuosa alcalina que contiene un 10\% de cloro activo, que le proporciona alto poder desinfectante.

Para preparar hipoclorito de sodio al $4 \%$ con fines de desinfección de superficies, recomendado para la eliminación de virus como el coronavirus, se aplicaron dos fórmulas básicas. Los mejores resultados los presentó la fórmula 2, que consiste en diluir una sustancia líquida de mayor concentración a una deseada, al resultado se le resta el volumen de la sustancia conocida y éste proporciona el volumen de agua destilada a mezclar para obtener el volumen y concentración deseada, la fórmula se expresa de la manera siguiente:

Donde:

$$
\begin{gathered}
C_{1} \cdot V_{1}=C_{2} \cdot V_{2} \\
V_{2}=\frac{\left(C_{1} \cdot V_{1}\right)}{C_{2}}
\end{gathered}
$$

$C_{1}=$ es la concentración inicial del hipoclorito de sodio

$V_{1}=$ volumen inicial del hipoclorito de sodio concentrado

$C_{2}=$ concentración final de la solución de hipoclorito de sodio diluida

$V_{2}=$ volumen final de la solución diluida

En ese caso, para conocer el volumen de agua con el que se debe diluir la solución concentrada de hipoclorito de sodio, basta realizar la operación de sustracción entre el volumen final y volumen inicial del hipoclorito de sodio concentrado, de la siguiente manera:

$$
\text { Volumen de agua }=V_{2}-V_{1}
$$

En nuestro caso, la preparación del hipoclorito de sodio al 4\% partió del hipoclorito de sodio al 12\%, como la sustancia concentrada, a lo que se le aplicó la ecuación de dilución universal. Comprobándose que, es más rápido y económico comprar las soluciones base y diluirlas en los Laboratorios de Ciencias, ya que de 1 galón de hipoclorito al 12\% se obtienen 3 galones de hipoclorito de sodio al $4 \%$ como solución desinfectante. Lo que significa que a 1 galón de hipoclorito de sodio al $12 \%$ se le agregan dos galones de agua destilada y se obtendrán 3 galones de hipoclorito de sodio al $4 \%$.

Como resultado de este proceso se obtiene un desinfectante de superficies y de calzado al alcance institucional, para disminuir el riesgo de infección por microorganismo, principalmente los coronavirus, coincidiendo con Ávila (2018), que el hipoclorito sódico es un compuesto oxidante de rápida acción utilizado a gran escala para la desinfección de superficies, ropa hospitalaria, desechos, descontaminante de salpicaduras de sangre, desinfección de equipos y mesas de trabajo resistentes a la oxidación, eliminación de olores y desinfección del agua.

\subsection{Obtención de alcohol etílico al $70 \%$ por vía fermentativa como agente desinfectante}

Las fermentaciones espontáneas de jugos y soluciones azucaradas almacenadas por la acción de las levaduras salvajes del ambiente, datan desde la antigüedad. Estas, fueron dando paso a las fermentaciones de jugos de frutas para la obtención de vinos, luego la cerveza y por último la producción de alcohol y bebidas destiladas. En este caso, nos interesa la obtención de alcohol con una concentración aproximadamente al 
70\% que es su mayor potencial bactericida. Lo que coincide con Kampf y Kramer (2004) que las concentraciones de $60 \%-80 \%$, tanto el etanol como el isopropanol, son potentes agentes viricidas, inactivando casi todas las especies de virus lipofílicos y muchos de los virus hidrofílicos. También tiene una potente actividad antifúngica, incluyendo levaduras.

La fermentación alcohólica es un proceso biológico en plena ausencia de aireoxígeno, originado por la actividad de algunos microorganismos que procesan los hidratos de carbono, por regla general azúcares: como la glucosa, la fructosa, la sacarosa y el almidón, para obtener como productos finales: alcohol en forma de etanol $\left(\mathrm{CH}_{3}-\mathrm{CH}_{2}-\mathrm{OH}\right)$, dióxido de carbono $\left(\mathrm{CO}_{2}\right)$ en forma de gas y unas moléculas de adenosintrifosfato (ATP) que consumen los propios microorganismos en su metabolismo celular energético anaeróbico .

Es así, que se realizaron tres diseños experimentales para elaborar el mosto (fermento alcohólico), dando el mejor resultado la fórmula 1, que consiste, en la preparación del mosto con $27 \mathrm{~L}$ de agua destilada, $250 \mathrm{~g}$ de levadura de pan y $6 \mathrm{Kg}$ de azúcar moreno. El proceso se basó en la fermentación alcohólica que Álvarez, (2018), describe como fermentación de líquidos azucarados mediante la fermentación biológica, dando como resultado alcohol y dióxido de carbono.

El proceso consistió en depositar $17 \mathrm{~L}$ de agua destilada en un barril plástico con tapadera de rosca, en $9 \mathrm{~L}$ de agua tibia. Seguidamente se diluyó $6 \mathrm{~kg}$ de azúcar moreno en agua y $250 \mathrm{~g}$ de levadura de pan en $1 \mathrm{~L}$ de agua tibia. Posteriormente se agrega el agua azucarada al barril y la solución de levadura. Se deja reposar sin tapadera en un lugar seguro con temperaturas entre $25^{\circ} \mathrm{C}$ y $30^{\circ} \mathrm{C}$ por 12 horas. Después se coloca la tapadera al barril, se cierra de manera hermética y se le coloca un airlock. El proceso se mantiene en observación durante 4 días, donde el $\mathrm{pH}$ del mosto ha sido ajustado entre 4 y 4.5 . El dia 5 cuando la levadura no está activa, se inicia el proceso de destilación mediante un destilador de alcohol artesanal.

En resumen, la secuencia de procesos para la obtención de etanol a nivel de laboratorio, fue fermentación y destilación. Lo que coincide con lo planteado por González y Jover (2002, citado en Campúes y Tarupí. 2011, p.48-51), en la investigación de obtención de alcohol a partir de jugo de caña, cachaza y melaza mediante la incorporación de dos niveles de fermentos. Quienes manifiestan que el proceso para la producción de etanol por vía fermentativa tiene dos etapas fundamentales: la fermentación y la destilación, utilizando temperaturas de fermentación del mosto de $25^{\circ} \mathrm{C}$ y $30^{\circ} \mathrm{C}$. Se consiguió un destilado del $30 \%$ de pureza en un rendimiento de $0.64 \mathrm{ml}$ de etanol/g de sustrato. La cantidad de producto destilado total fue de 1000 $\mathrm{ml}$ de etanol. El grado de alcohol fue determinado en la práctica, mediante un densímetro de alcohol, el cual mide alcohol potencial específico por volumen del o vol\% al $100 \mathrm{vol} \%$, la escala mínima es de 1 grado, dando como resultado alcohol al 80\%, el que se diluyó al 70\%, alcanzado el propósito planteado.

\section{Conclusiones}

1. Los laboratorios de ciencias de la universidad URACCAN, presentan las condiciones básicas para elaborar jabón, preparar hipoclorito de sodio al 4\% y obtener alcohol etílico al 70\%, como agentes desinfectantes.

2. Las propiedades físicas y el desempeño de los productos obtenidos son de calidad y a menor costo que en el mercado local.

3. La disponibilidad y el acceso de los insumos mejorará si estos se producen en los laboratorios de ciencias de los recintos y extensiones de URACCAN.

4. Con los resultados obtenidos, se puede proyectar un plan de producción continuo con perspectiva de sostenibilidad.

\section{Agradecimiento}


Esta publicación obtuvo el financiamiento de: El Fondo de Asistencia Internacional de los Estudiantes y Académicos Noruegos (SAIH).

\section{Lista de referencias}

Alvarez, Y. (2018). Alcohol etílico. Proceso artesanal. Ingenio San Antonio. Nicaragua.

Ávila, N. (2018). Protocolo de uso y preparación de hipoclorito de sodio. Clínica Girón. Gestión de Recursos Físicos y Servicios Básicos. Santander. Colombia.

Barbosa, C. (2012). Estudio de factibilidad para la creación de una microempresa productora y comercializadora de jabón artesanal. Ciudad de Quito. Ecuador.

Campúes, J y Tarupí, J. (2011). Obtención de alcohol a partir de jugo de caña, cachaza y melaza mediante la incorporación de dos niveles de fermentos. Universidad Técnica del Norte. Facultad de Ingeniería en Ciencias Ambientales y Pecuarias. Ybarra. Ecuador.

Center for Disease Control and Prevention [CDC]. (2020b). How to protect yourself. Fuente:https://www. cdc.gov/coronavirus/2019-ncov/prepare/prevention.html

Hernández Sampieri, R. (2003). El proceso de investigación y los enfoques cuantitativos cualitativos: Hacia un modelo integral, en metodología de la investigación social. Mc Graw Hill. México.

Herrera, J; Padilla, V; Cárdenas, M; Carrero, Y; Alayón, M. (2011). Mejora del proceso de destilación artesanal para la producción de etanol. Grupo Caña de Azúcar. Laboratorio de Investigación en Ciencias Básicas e Ingeniería (LICBI). Universidad Nacional Experimental del Táchira. República Bolivariana de Venezuela.

Kampf G \& Kramer A. (2004). Epidemiologic background of hand hygiene and evaluation of the most important agents for scrubs and rubs. Clin Microbiol Rev. 2004 Oct;17(4):863-93.

Kasper, C. (2020). El placer del jabón natural. Como elaborar el jabón vegetal desde tu propia cocina. Suiza.

OPS. (2020). Coronavirus. Brote de enfermedad por el coronavirus (covid-19). Organización de las Naciones Unidas. Fuente:https://www.paho.org/es/temas/coronavirus

Oliva Marín JE. (2020). SARS-CoV-2 origen, estructura, replicación y patogénesis. Alerta 2020; 3(2) DOI: https://doi.org/10.5377/ alerta. v3i2.9619

Ramos, J. (2016). Cómo hacer jabones: Aprende a formular recetas de jabón por saponificación. Madrid. España.

Torres, K. (2016). Hipoclorito de sodio como agente desinfectante. Seguridad Biológica. Ciudad de México. México.

Thordarson, P. (2020). ¿Por qué el jabón funciona muy bien contra el nuevo Coronavirus (SARS-COV-2)? Fuente:https://twitter.com/PalliThordarson/status/1236549305189597189.

UnitedStatesEnvironmentalProtectionAgency[EPA].(2020).ListN:DisinfectantsforUseAgainstSARS-CoV-2. Fuente:https://www.epa.gov/pesticide-registration/list-n-disinfectants-use-against-sars-cov-2

URACCAN. (2020). Laboratorios de Ciencias de la URACCAN. Reglamento. Regiones Autónomas de Nicaragua. Nicaragua. 
URACCAN

World Health Organization [WHO]. (2020d). Water, sanitation, hygiene, and waste management for the COVID-19 virus. Fuente:https://www.who.int/publications-detail/ water-sanitation-hygiene-and-waste-managementfor-covid-19

World Health Organization [WHO]. (2020e). Coronavirus disease (COVID-19) advice for the public. Fuente:https://www.who.int/emergencies/diseases/novel-coronavirus-2019/advice-for-public 